\title{
PROTEGER A VIDA OU DEIXAR MORRER? ATUAÇÃO DOS ASSISTENTES SOCIAIS NA SAÚDE PÚBLICA COM A 'RALÉ'
}

\author{
PROTECT LIFE OR ALLOW TO DIE? PERFORMANCE OF SOCIAL \\ WORKERS IN PUBLIC HEALTH WITH THE 'RABBLE'
}

¿PROTEGER LA VIDA O DEJAR MORIR? ACTUACIÓN DE LOS ASISTENTES

SOCIALES EN LA SALUD PÚBLICA CON LA'PLEBE'

Josilene Barbosa do Nascimento ${ }^{1}$

Resumo Este artigo problematiza a singularidade da desigualdade social brasileira, produtora de uma 'ralé' estrutural e legitimada por uma hierarquia valorativa que separa pessoas em gente e subgente, cidadãos e subcidadãos; pessoas que devem ser vistas e respeitadas, de um lado, e pessoas desdenhadas, desvalorizadas, de outro. Posteriormente, abordamos como acontece a reprodução do esquema da desigualdade social na saúde pública, considerada de péssima qualidade e que contradiz, na prática, os preceitos constitucionais pelos quais o Sistema Único de Saúde foi criado, não beneficiando a proposta idealizada em seu cerne de garantir cidadania inclusiva e igualitária. Finalmente, propomos reflexões em torno da atuação dos assistentes sociais na saúde pública a partir do atendimento direto aos usuários, principalmente por meio das ações educativas, considerando-as como uma oportunidade para trabalhar, com a 'ralé', aspectos que mantêm tal classe exatamente numa situação de subcidadania e, por isso, receptora de atendimento desumano nos serviços públicos de saúde. Palavras-chave desigualdade social; saúde pública; atuação dos assistentes sociais.

\begin{abstract}
This article discusses the uniqueness of Brazilian social inequality, which produces a structural 'rabble' legitimized by a value hierarchy that segregates people into people and sub-people, citizens and sub-citizens; people who must be seen and respected, on the one hand, and people to be disdained, devalued on the other. Subsequently, we discuss how the social inequality scheme is reproduced in public health, which is considered of poor quality and, in practice, contradicts the constitutional precepts pursuant to which the Unified Health System was created, not benefiting the idealized proposal at its core to ensure inclusive, egalitarian citizenship. Finally, we propose reflections about the role social workers play in public health through the provision of direct service to users, especially through educational actions, considering them as an opportunity to work with the 'rabble,' aspects that maintain such class exactly in a situation of sub-citizenship and, therefore, receiving inhumane care from public health services.
\end{abstract}

Keywords social inequality; public health; performance of social workers. 


\section{Introdução}

Valor diferencial dos individuos, segundo a hierarquia de classe, sempre existiu. A vida dos ricos e poderosos sempre foi tida como 'mais vida' do que a dos miseráveis. (...) É esse o ' $x$ ' do problema: mostrar que qualquer vida, pobre ou rica, famosa ou anônima, deve ser respeitada como um bem em si (Costa, 1994).

A crônica escrita pelo psicanalista Jurandir Freire Costa intitulada "Desiguais na vida e na morte", publicada na Folha de S.Paulo em 22 de maio de 1994 no caderno Mais!, reflete sobre o valor diferencial entre duas pessoas: de um lado o piloto de Fórmula 1 Ayrton Senna, que faleceu em acidente de trabalho naquele mês, e de outro Rosilene, uma empregada doméstica, que morreu atropelada na avenida das Américas, Barra da Tijuca, Rio de Janeiro, também em maio de 1994. Rosilene ficou estendida na estrada por duas horas, e nesse meio-tempo os carros passaram por cima do corpo, esmagando-o de tal modo que a identificação só foi possível pelas impressões digitais. Costa (1994) enfatiza que talvez muitos que passaram por cima do corpo de Rosilene, esmagando-a, choraram, dias antes, a morte de Ayrton Senna. Luto e tristeza por um, desprezo e indiferença por outro. O absurdo, aponta Costa (1994), é tornar Senna um herói nacional e tratar com descaso a vida dos mais humildes.

No Brasil, atualmente, nos meios de comunicação de massa, quase que cotidianamente, são veiculadas notícias sobre o modo violento como policiais tratam os pobres. Sobre o assunto, Machado e Noronha (2002) enfatizam que essa violência policial direcionada a certos indivíduos ou grupos, também denominada de violência oficial, é uma realidade nas sociedades contemporâneas. Entretanto, o seu modo de manifestação dependerá do grau de tolerância, tanto governamental quanto da população em geral, visto que, em determinados lugares, é necessário mais vigilância sobre a ação policial do que em outros. Tal diversificação de comportamentos, seja da polícia, seja da população, remete a alguns aspectos essenciais, como a direção governamental no uso da violência; "a consciência de cidadania; o nível de aceitação social da violência para resolver conflitos e o padrão de relacionamento entre governo e população visando regular a cidadania e possibilitar o controle social sobre os órgãos governamentais" (Machado e Noronha, 2002, p. 198).

É nesse sentido que a violência oficial está estreitamente relacionada à violência estrutural, manifestando-se, certamente, nas desigualdades sociorraciais. Porém, tal violência não pode ser reduzida a esta última, considerando que o "aparelho policial participa ativamente na manutenção e reprodução da ordem social" (Machado e Noronha, 2002, p. 198). Assim, o modo como tal aparelho age e trata populações pobres e, na sua maioria, não brancas depende de fiscalizações institucionais externas e internas ao aparelho policial. Machado e Noronha 
(2002) afirmam ainda que é exatamente a falta ou redução desses controles que possibilita que a violência estrutural seja transformada em agressão direta e interpessoal, culminando em modos de vitimização e insegurança que favorecem e legitimam a intolerância, servindo, nesse caso, como álibis para abusos policiais.

Atualmente, no caso brasileiro, por exemplo, a percepção de que está havendo a perda de controle sobre a criminalidade e os criminosos 'permite' que determinados setores da sociedade legitimem comportamentos autoritários e intolerantes, apoiando, inclusive, excessos da polícia contra responsáveis por grandes ou pequenos crimes. Nesse contexto, podemos entender, também, os casos de linchamentos, ou seja, a 'justiça' realizada pelos cidadãos comuns que atingem os 'supostos criminosos' mais pobres. Mas por que a vida dos mais pobres é tão desvalorizada? Será que a vida de uns vale mais que a vida de outros? Para responder a esses questionamentos, tomamos os estudos de Souza (2003a, 2003b) sobre a construção social da subcidadania no Brasil.

Para Souza (2003a), o imaginário social dominante no Brasil representa 'o brasileiro' como se fosse um tipo social homogêneo, independentemente de sua classe ou pertencimento social. A ideia é de que esses indivíduos, essencialmente análogos, “apenas diferissem na renda que ganham e que o progresso econômico seria, portanto, o Deus ex machina ao qual caberia resolver problemas como desigualdade, marginalidade e subcidadania" (Souza, 2003a, p. 51, grifos do autor). Ele enfatiza que existe entre nós, brasileiros, uma crença no progresso econômico, de que a expansão do mercado resolveria todos os nossos problemas sociais. Aqui, a desigualdade social seria "algo temporário, modificável por altas taxas de crescimento econômico, a qual, de algum modo obscuro, terminaria por incluir todos os setores marginalizados" (Souza, 2003a, p. 58). Ao contrário desse argumento, o autor lembra que entre os anos de 1930 e 1980 o Brasil apresentou um dos maiores crescimentos econômicos do mundo, porém as taxas de desigualdade, marginalização e subcidadania jamais foram alteradas radicalmente, inclusive na atualidade. Ele considera que esse tipo de argumento é desatento aos aspectos morais e políticos que são importantíssimos para uma real estratégia inclusiva.

Ora, nenhuma das sociedades modernas que igualizaram e generalizaram "um tipo humano para todas as classes, como uma precondição para uma efetiva e atuante ideia de cidadania, conseguiu esse intento como efeito colateral unicamente do desenvolvimento econômico" (Souza, 2003a, p. 58). ${ }^{2}$ A explicação que considera a marginalidade como determinada por problemas sociais que serão corrigidos por medidas econômicas contribui, assim, para sua permanência e naturalização.

Para esclarecer o tema da desigualdade social no Brasil, Souza (2003a, 2003b, 2006) desvela o potencial constituidor e legitimador das diferenças sociais tidas como naturais e legítimas, mascaradas pela fictícia existência de uma igualdade de oportunidades e uma universalidade de direitos. 
Com base no exposto, aqui pretendemos, inicialmente, problematizar a desigualdade social no Brasil para, logo após, refletir sobre como essa desigualdade repercute no atendimento ofertado pelos serviços públicos de saúde - compreendendo que, atualmente, um dos maiores problemas sociais do Brasil é a precariedade da saúde pública. À primeira vista, é o nosso sistema de saúde deficiente, que impossibilita à população um atendimento de qualidade no setor saúde, seja de baixa, seja de média ou alta complexidade, o responsável pelo nosso quadro de desigualdades sociais, surgindo daí a ideia de que esse setor - juntamente com a educação - merece investimentos prioritários por parte do Estado. Luna (2009), questionando esse argumento, considera que ele é equivocado, pois inverte as causas de nossas 'feridas' sociais pelos seus efeitos. A autora considera que a saúde não é uma das causas da desigualdade social, mas, ao contrário, apenas reproduz o esquema da desigualdade que se perpetua em nosso país.

Entendendo que a desigualdade social produz e legitima a 'ralé, , ${ }^{3}$ sendo um fenômeno de massa suficiente para condenar $1 / 3$ da população brasileira a uma vida marginal nas dimensões existencial, política e econômica (Souza, 2003b), e que o abandono social e político de tal classe é consentido por toda a sociedade - inclusive pela própria classe de indivíduos precarizados da 'ralé' -, elegemos a atuação dos assistentes sociais, via ações educativas, como imprescindível para a reversão dessa realidade. Em prol, portanto, da garantia de atendimentos humanizados e de qualidade ofertados pela rede pública de saúde.

\section{Desigualdade social no Brasil e produção da 'ralé'}

Souza (2003b, p. 168) parte da pressuposição de que a noção de 'ideologia do desempenho' permite pensar a dimensão sociológica da produção da distinção social, percebendo que "as pessoas não são aquinhoadas equitativamente com o mesmo reconhecimento social por sua dignidade".

A 'ideologia do desempenho' se baseia na tríade meritocrática que envolve qualificação, posição e salário. A qualificação, que reflete a importância do conhecimento com o desenvolvimento do capitalismo, é o primeiro e mais importante ponto que condiciona os outros dois. A 'ideologia do desempenho' é exatamente uma 'ideologia' porque não apenas "estimula e premia a capacidade de desempenho", mas também "legitima o acesso diferencial permanente a chances de vida e apropriação de bens escassos" (Souza, 2003b, p. 169). É essa combinação da tríade da 'ideologia do desempenho' que faz do indivíduo um 'sinalizador' completo e positivo do 'cidadão completo'. “A tríade torna também compreensível por que apenas através da categoria do 'trabalho' é possível se assegurar de identidade, autoestima e reconhecimento social" (Souza, 2003b, p. 169), ou seja: é o trabalho que parece estar por trás da "avaliação objetiva do valor relativo" de cada qual nessa dimensão: enxerga-se somente a função e não a pessoa. 
Segundo Souza (2003a, 2003b, 2009), com base nas noções de habitus e de 'ideologia do desempenho', é possível compreender por que existem classes positivamente privilegiadas, reconhecidas e valorizadas, por um lado, e classes desvalorizadas, desdenhadas, por outro. É necessário entender, então, que assim como os "'capitais impessoais' que constituem toda hierarquia social e permitem a reprodução da sociedade moderna" (Souza, 2009, p. 21), o capital cultural e o capital econômico também são diferentemente apropriados. Vejamos, então, as noções de habitus.

Souza (2003a, 2003b, 2006), entendendo que o ponto de partida de Bourdieu $(1983,2007)$ é unilateral, propõe uma subdivisão interna à categoria de habitus ${ }^{4}$ elaborada pelo autor francês, com o propósito de lhe conferir um caráter histórico mais diverso, plural, inexistente na análise bourdieusiana. Desse modo, no lugar de falar de habitus somente no sentido genérico, como faz Bourdieu, quando o aplica apenas em situações específicas de classe num contexto sincrônico, "acho mais interessante e rico (...) falar de uma pluralidade de habitus" (Souza, 2003a, p. 62, grifos do autor). Assim, Souza (2003a) apresenta o 'habitus primário' como a generalização das precondições sociais, econômicas e políticas que permitem ao sujeito ser útil, digno e cidadão, no sentido de reconhecimento intersubjetivo como tal; e o 'habitus precário' como o limite do 'habitus primário' para baixo, um tipo de personalidade e disposições de comportamento que não atendem às demandas objetivas para que, como indivíduo ou como um grupo social, possa ser considerado produtivo e útil em uma sociedade de tipo moderno e competitivo, usufruindo de reconhecimento social.

O capital cultural, na forma de conhecimento técnico e escolar, adquiridos a partir da incorporação do 'habitus primário', o qual permite domínio da razão sobre as emoções e pulsões irracionais, exaltação das virtudes do cálculo prospectivo - que possibilita uma visão de que o futuro é mais importante do que o presente, autorresponsabilidade, disciplina etc. --, é imprescindível ao indivíduo tanto para desenvolver capacidades fundamentais para adquirir qualquer tipo de aprendizado quanto para ingressar no mercado de trabalho competitivo. Esse habitus é incorporado pelas classes médias brasileiras, fazendo-a uma das classes dominantes. "A classe alta se caracteriza pela apropriação, em grande parte pela herança de sangue, de capital econômico, ainda que alguma noção de capital cultural esteja sempre presente" (Souza, 2009, p. 21).

Souza (2009) argumenta que existe também uma classe inteira de indivíduos desprovidos não apenas de capital cultural e econômico, mas das precondições sociais, morais e culturais ('habitus primário') que permitem essa apropriação. Esses indivíduos, pela inexistência dos pressupostos mínimos para uma capacidade de competição bem-sucedida (ou seja, são detentores de um 'habitus precário'), não conseguem competir em pé de igualdade na sociedade do tipo capitalista. 
O 'habitus precário', como afirma Souza (2006, 2009, 2010), é o responsável pela marginalização de milhões de brasileiros. E a 'cegueira' existe porque há uma naturalização da desigualdade, no sentido de que ela não chega à consciência de suas vítimas. O sucesso do indivíduo é considerado mérito pessoal, deixando de evidenciar que são os privilégios de nascimento ou econômicos que possibilitam a determinadas classes sociais - as privilegiadas - o acesso a boas escolas, ao tempo livre para estudar, a cursos de línguas estrangeiras etc., e principalmente a incorporação de um habitus adequado à conquista do sucesso educacional, profissional e econômico.

Apenas quando as precondições para o reconhecimento objetivo dos papéis de produtor e cidadão estão dadas pode o indivíduo obter sua identidade pessoal e social de forma completa. É o poder legitimador, portanto, da 'ideologia do desempenho' que irá determinar aos sujeitos e grupos sociais excluídos, pela inexistência dos pressupostos mínimos para uma capacidade de competição bem-sucedida, seu não reconhecimento social e sua ausência de autoestima. A 'ideologia do desempenho' é opaca, sutil, intransparente, pois 'aparece' à consciência cotidiana dos indivíduos como se fosse efeito de princípios universais e neutros, abertos à competição meritocrática (Souza, 2003b).

Se o princípio básico do consenso transclassista é o princípio do desempenho, a aceitação e a internalização generalizada desse princípio fazem com que a inadaptação e a marginalização de certos setores possam ser percebidas pela sociedade incluída - e também pelas próprias vítimas 'encerradas' no 'habitus precário' - como um 'fracasso pessoal' (Souza, 2003a, 2003b, 2006).

A tese do sucesso como mérito pessoal culpabiliza as classes desprivilegiadas pelo seu próprio destino ou desempenho fracassado, por serem preguiçosas e incapazes, deixando de evidenciar que, na realidade, tais classes não tiveram acesso aos privilégios sociais herdados pelas classes médias e altas. Essa classe social, inapta às demandas produtivas e sociais, no caso brasileiro, é denominada por Souza (2009) de 'ralé estrutural', uma 'classe social' caracterizada por não possuir as precondições para o trabalho técnico no setor competitivo do capitalismo, pois se forma pela ausência de incorporação dos capitais impessoais, como o capital cultural ou técnico, do mundo moderno.

Nesse sentido, a miséria da 'ralé' "é produzida objetivamente não apenas sob a forma de miséria econômica, mas também sob a forma de miséria emocional, existencial e política" (Souza, 2006, p. 10). A reprodução de classes sociais 'ralés', marginalizadas, "envolve a produção e a reprodução das pré-condições [sic] morais, políticas e culturais da marginalidade" (Souza, 2006, p. 10) (o 'habitus precário'), como ausência de autoestima, autoconfiança, reconhecimento social, aprendizado familiar de papéis básicos e uma escola de qualidade (ou seja, ausência de um capital cultural adequado às exigências do mercado capitalista). 
Obviamente, esse não reconhecimento da 'ralé', a desigualdade social, se reflete nos serviços públicos de saúde. Mas como não pensar na 'naturalização' de serviços de saúde de primeira qualidade para as classes privilegiadas classes média e alta - e de segunda qualidade para os mais pobres? E quanto aos casos de profissionais da saúde que atendem seu paciente de modo respeitador e atencioso nos espaços das instituições privadas de saúde, como clínicas particulares, e de outro modo, nas instituições públicas de saúde, vitimizam seus pacientes cometendo maus-tratos e negligência?

Certamente, não desejamos destacar as falhas humanas que todas as pessoas, ao serem atendidas, pela rede pública ou privada de saúde, estão sujeitas a experimentar. Porém, a saúde pode reproduzir o esquema da desigualdade social que se perpetua em nosso país; por isso, problematizar as causas da debilidade dos serviços públicos de saúde é uma forma de compreendermos algo importante acerca da nossa sociedade: que uma hierarquia valorativa entre os tipos humanos segrega e classifica seus membros de forma a valorizar uns em detrimento de outros.

\section{A reprodução do esquema de desigualdade social legitimada pela rede pública de saúde: deixar morrer...}

A desigualdade social, que segrega e classifica as pessoas, de modo a valorizar umas em detrimento de outras, pode refletir a lógica a lógica e o modo de agir de nossas instituições. É nesse sentido que “o mau funcionamento de um setor público, como no caso da saúde, deve ser repensado tendo em vista seu público-alvo principal" (Luna, 2009, p. 305) - no caso a população carente, a 'ralé', que necessita dos serviços públicos de saúde e os procura. Tal população, de milhões de brasileiros, cotidianamente é condenada a um dia a dia humilhante, desumano, devido a um tipo de violência sofrida - a 'violência simbólica', que não 'aparece' como violência, mas que torna possível a naturalização de uma desigualdade social absurda como a brasileira:

\footnotetext{
A 'legitimação da desigualdade' no Brasil contemporâneo, que é o que permite a sua reprodução cotidiana indefinidamente, nada tem a ver com um passado longínquo. Ela é reproduzida cotidianamente por meios 'modernos', especificamente 'simbólicos', muito diferentes do chicote do senhor de escravos ou do poder pessoal do dono de terra e gente, seja esta gente escrava ou livre, gente negra ou branca (Souza, 2009, p. 15).
}

Aqui, então, lembrando que existem formas 'novas' e 'modernas' de se legitimar a dominação, objetivamos indicar e problematizar, com base em alguns exemplos pontuais, como as debilidades no funcionamento das instituições públicas de saúde se harmonizam com a desigualdade social, legi- 
timando-a, reproduzindo-a, o que significa que na prática elas contradizem os preceitos constitucionais pelos quais o Sistema Único de Saúde (SUS) foi criado, não beneficiando a proposta idealizada em seu cerne: defender cidadania inclusiva e igualitária.

Ao contrário disso, a segmentação de clientelas entre a assistência pública e a privada, esta última formalizada pela regulamentação da assistência supletiva no final de 1990, evidencia a inviabilidade do ideal de saúde como 'um direito de todos e um dever do Estado'. Se o SUS já não é o 'único' sistema em atuação, menos ainda será a sua aplicabilidade enquanto sistema de abrangência universal (Luna, 2009, p. 306, grifos da autora).

É certo que a trajetória política de saúde no Brasil caracterizou-se pela segmentação entre duas formas de assistência - a assistência médica individual, para aqueles inseridos no mercado formal que contribuíam com a Previdência Social; e as ações de saúde de caráter coletivo destinadas aos 'pobres', caracterizadas por um modelo de higienização da sociedade, como necessidade de controle de epidemias e de moléstias consideradas como 'doenças de pobre'. Apesar dos avanços conseguidos por meio da Reforma Sanitária, que culminou na criação do SUS e na crítica à mercantilização da saúde, o atual sistema de saúde brasileiro permanece segregado, agora entre os serviços destinados aos que 'podem pagar' um plano de saúde e aos que 'não podem pagar' (Luna, 2009).

Luna (2009) demonstra ainda como o sistema público de saúde, em relação às suas debilidades, é favorável a instaurar um padrão que ela denomina de 'má-fé institucional', compreendendo essa realidade como uma inclinação constante das instituições públicas de saúde em abandonar as ações que fazem parte, oficialmente, de sua competência. A 'má-fé' também representa a forma de "funcionamento dessas instituições públicas de saúde que expõem seus funcionários e pacientes a conflitos de classe a todo instante" (Luna, 2009, p. 306). Embora esses conflitos possam acontecer na rede privada, no setor público - em grande parte porque é destinado aos 'que não podem pagar', os considerados 'ralé' - o conflito de classe torna-se comum, apesar de 'dissimulado'. Entende-se que em muitos casos estes são considerados, na hierarquia valorativa humana, desvalorizados, subcidadãos.

Com base nesses argumentos, problematizamos aqui ações ocorridas em determinadas instituições públicas de saúde, chamando a atenção para outras dimensões do problema da saúde pública, muitas vezes não vistas ou discutidas, que são importantíssimas ao entendimento do modo como seus serviços alcançam os pacientes das classes menos favorecidas economicamente. É destacada nos exemplos mencionados a desvalorização moral, social e política das pessoas que mais utilizam o SUS, a partir da falta de legitimação 
do reconhecimento de sua cidadania, que está subentendida no tratamento desigual recebido pelas pessoas de outras classes.

Vejamos um exemplo na prática. Em dezembro de 2013 foi amplamente divulgado na mídia um caso de humilhação social sofrida pela mãe de uma menor que procurou o Hospital e Pronto Socorro da Criança, na Zona Oeste de Manaus (AM), com o intuito de conseguir atendimento para a sua criança, que apresentava sintomas de vômito e diarreia. Uma médica pediatra, que estava conversando com outro profissional no corredor do hospital, após se recusar a atender a criança, ofendeu verbalmente a mãe quando ela questionou a demora do atendimento, chamando-a, supostamente, de "macaca, suja, pobretona e preta velha". A médica, em defesa própria, negou o acontecido, informando que a mãe havia sido grosseira com ela, no momento de questionar o atendimento. Testemunhas informaram sobre o ocorrido, inclusive comunicando que outros médicos saíram em favor da pediatra, deixando de atender os pacientes por alguns minutos.

Também é frequente na mídia a divulgação de comportamentos médicos desonestos, como, por exemplo, cobranças indevidas de serviços médicos já custeados pelo SUS, deixando muitos pacientes e familiares apavorados diante dessa cobrança, principalmente quando o atendimento ou procedimento, incluindo cirurgias, deve ser realizado com urgência. É comum, diante dessas exigências, famílias de baixa renda venderem algum bem, como uma moto ou um carro, contrair empréstimos etc. para pagar algo já custeado pelo SUS.

Luna (2009) apresenta exemplos de casos verídicos de maus-tratos e negligência à saúde da população que procura os serviços públicos de saúde, que ela considera um "quadro desonroso da saúde pública no país" (Luna, 2009, p. 315). Problematiza os relatos de uma estagiária de serviço social que, na época, estava concluindo o curso numa cidade do Rio de Janeiro em especial sobre um evento, considerado por ela um dos mais importantes, por tê-lo presenciado quando conversava com uma paciente que havia se acidentado, instalada no corredor do hospital juntamente com o marido, que teve a coluna imobilizada por um colete. A paciente, na ocasião, pediu a um médico que olhasse e ajudasse a arrumar o colete do seu marido, pois estava mal colocado. Vejamos o relato:

O médico gritava com o paciente: "Você tá vendo isso aqui? O colete é para imobilizar, I-MO-BI-LI-ZAR! Sabe o que que é isso?" Ele falava gritando com o paciente. Aí ele [paciente] falou assim: "Eu sei, mas..." O cara não conseguia nem falar! “Eu sei, mas não sei como é que coloca! Você pode me ajudar?" [retruca o paciente, humildemente]. Aí fazia assim com força no colete! [gesticula reproduzindo o movimento do médico]. O cara gritava de dor: "Tá doendo!" “É pra doer! Pra você aprender a não tirar do lugar!" [médico]. "Mas eu não tirei!" [responde temeroso o paciente]. $\mathrm{O}$ cara não tinha como tirar o colete porque ele estava sem força nenhuma! E esse 
colete... ele explicou, gritando, que não havia a menor necessidade, "o colete é para imobilizar pra você não sentir essa fraqueza que você tá sentindo nas pernas. Você nunca mais vai andar se o colete não ficar no lugar certo, então você deixa ele aqui!" (estagiária de serviço social apud Luna, 2009, p. 316).

A paciente tenta amenizar a situação, mas quando se dirige ao médico é humilhada verbalmente por ele. Nenhuma contestação foi feita contra esse ato de violência. A própria estagiária, estarrecida com o ato desumano e hostil contra o rapaz do colete e sua esposa, não falou nada, sentiu-se com as mãos atadas, impotente. Lembrou-se do cuidado humanizado, que é um direito do paciente, que ela - como estagiária de serviço social - deveria garantir. Justamente quando o seu trabalho deveria assegurar os direitos do paciente, ela não conseguiu fazer nada. E por quê? O que imobilizou a estagiária de serviço social e todos que assistiram à cena? No caso da estagiária, será que foi a falta de experiência e segurança?

A estagiária disse que não, que as assistentes sociais de longa data, inclusive as supervisoras de plantão, compartilhavam do mesmo sentimento. As suas ações sempre eram limitadas diante das adversidades e elas sentiam 'medo' em pedir uma informação ou ajuda a um médico, e mesmo aos auxiliares de enfermagem e enfermeiros em geral. "Pedir ajuda pode resultar em tomar um 'fora', ou algum tipo de constrangimento, muitas vezes na frente dos pacientes e colegas de trabalho" (Luna, 2009, p. 317). O trabalho das assistentes sociais demanda um esforço imenso quando têm que batalhar pelos direitos e o bem-estar dos pacientes. É uma luta contra a força das ações opostas ao que elas pretendem fazer, como por exemplo a 'má vontade' de muitos que trabalham nos serviços de saúde, principalmente os médicos ou qualquer profissional com autoridade diante delas.

Parece ficar implícito na prática que o importante é apenas salvar a vida do paciente; o resto é adicional e mesmo desnecessário. Não interessam as demandas sociais e psicológicas, já que o paciente nada mais é que um corpo que médicos e enfermeiros são pagos para tratar. Temos com isso uma noção animalizada sobre a vida e a saúde, algo que os princípios do SUS combatem. Mas, ainda assim, mesmo com a preocupação com a saúde num âmbito restrito ao corpo, ocorrem eventos que nem o mais bem-intencionado profissional pode concordar (Luna, 2009, p. 317-318).

E por que não aconteceram impugnações contra a humilhação social sofrida pelo paciente e sua esposa vindas daqueles que assistiram à cena, como outros pacientes, familiares de pacientes, profissionais etc.? Para Luna (2009), isso só é possível pelo fato de todos que assistiram à cena, mesmo contrários a essa maneira tão humilhante e violenta de tratar o outro, sentirem-se inferiores, sem autoridade, diante da pessoa que a praticou (ou pratica), não sendo, 
nesse sentido, capazes de confrontá-la. Afinal, mesmo não concordando com a situação, quando se calam, acabam por legitimar e consentir a humilhação. Nenhum dos espectadores estava em condições de encarar o médico, "aquele que agrega em si o poder maior de controlar a vida” (Luna, 2009, p. 318), e que, talvez por isso, possua tamanho prestígio e autoridade.

A própria forma de funcionamento da instituição médica pode ocasionar vulnerabilidade dos seus profissionais ou das suas condições de trabalho, acarretando danos ao paciente.

O funcionamento da unidade médica ainda favorece a ocorrência de conflitos entre os próprios profissionais da área, visto que a divisão do trabalho estabelece uma hierarquia entre as funções mais imprescindíveis a esse funcionamento e aquelas cotadas como menos necessárias, ou pelo menos não tão imperiosas (Luna, 2009, p. 318-319).

É nesse contexto que haverá maior importância social para o trabalho que estiver no topo dessa hierarquia, os trabalhos considerados mais necessários, permitindo ao trabalhador maior prestígio e status. Tal ideia compactua com a ideologia do mérito disseminada socialmente, de que as pessoas consideradas que mais estudam - e com isso mais se qualificam profissionalmente - devem ser recompensadas com os maiores salários e prestígio. Assim, a estagiária de serviço social informou que alguns(mas) médicos(as) estão ressentidos(as) com outros profissionais que conquistaram o direito de ganhar o mesmo salário, como o caso dos(as) assistentes sociais, percebendo certo desdém por parte de um deles, que a desprezou quando foi pedir para ele explicar à família de um paciente a razão do seu falecimento, pois além de ela não possuir conhecimento técnico para isso, não é função dela e sim do médico (Luna, 2009). O referido médico disse que não devia satisfações de sua conduta a uma estagiária de serviço social: “Minha filha, já morreu, eu não tenho mais que explicar nada, não" (estagiária de serviço social apud Luna, 2009, p. 319).

Primeiramente, se a prioridade da saúde pública no país fosse para a promoção e prevenção da saúde, todos os profissionais cotados para esse tipo de atendimento, supostamente, seriam valorizados, incluindo assistentes sociais. Mas a assistência pública à saúde, tal como é praticada na atualidade, é marcada pelo serviço de natureza hospitalar, focalizada nos atendimentos médicos e numa visão biologicista/biomédica do processo saúde/doença, voltando-se prioritariamente para ações curativas - por isso a importância e centralidade do médico, principalmente especialista. Em segundo lugar, com a atitude de desprezar a estagiária, o médico valida sua superioridade 'prepotente' de classe, abstendo-se de cumprir com um dos princípios do SUS, que assegura ao paciente a ciência do seu estado de saúde e, aqui especificamente, no caso do falecimento do paciente, informar a sua família as causas de seu óbito. Luna (2009) ainda 
relata que a estagiária chegou a ouvir de uma mulher a reclamação de que seu marido fora operado sem ninguém lhe ter explicado os motivos.

Esses casos se assemelham, pois sugerem que não é necessário explicar a morte ou a deliberação de uma intervenção médica quando se trata da vida ou saúde de um paciente 'qualquer'. Isso porque, na realidade, são pessoas que estão sujeitas às decisões das classes dominantes em todas as dimensões e simplesmente pessoas que, para morrer, do mesmo modo que quando vivas, não precisam ser justificadas (Luna, 2009, p. 319).

É percebido que sempre diante de histórias de práticas de abuso e negligência, que se constroem em torno de vilões e vítimas, na maioria das vezes a figura do médico é central. “Quando não são heróis, as figuras de médicos carrascos e arrogantes", como também desonestos e mercenários, "alojam-se facilmente em nosso imaginário" (Luna, 2009, p. 320). Afinal, foi um médico que se recusou a oferecer informações sobre o óbito de um paciente para seus familiares, humilhando, também, uma estagiária de serviço social com o uso de palavras grosseiras, revelando o que está implícito na negação da informação: “a falta de necessidade de explicar a morte de alguém cuja vida é insignificante diante dos olhos de toda a sociedade" (Luna, 2009, p. 319). Contudo, a imagem do médico carrasco e desumano ofusca a ampla dimensão dos maus-tratos, pois, além de uma questão de opressão da classe dominante sobre as dominadas, não percebe que a própria instituição incentiva tanto o erro como a discriminação de todos os envolvidos.

Atitudes de desdém e maus-tratos envolvem, inclusive, as classes baixas, as que mais se aproximam da 'ralé'. É também por meio delas que os pacientes estão sujeitos a sofrer um atendimento ruim, desumano. Basta perceber na prática os boicotes de auxiliares de enfermagem aos pacientes de baixa renda, a 'ralé'. Com tais atitudes, evidenciamos, então, "um conflito de classes entre as pessoas que, por estarem social e geograficamente perto da ralé, lutam para fugir de estigmas que são atribuídos às frações delinquentes da mesma, e pessoas que são enquadradas em tais estigmas" (Luna, 2009, p. 320). É aqui que os técnicos de enfermagem concedem um tratamento pouco humanizado, de péssima eficiência, ao bandido, ao usuário de drogas, à mulher de 'vida fácil' etc., sendo o modo mais comum de legitimar e assinalar um distanciamento em relação aos estigmas e com isso a "recorrente e desesperada tentativa de evitar seu próprio rebaixamento como pessoa" (Luna, 2009, p. 320).

O perfil do paciente que mais sofre com o mau atendimento e até com a discriminação explícita é aquele associado à imagem de delinquente, bastando, para isso, apresentar uma simples tatuagem. "A discriminação corresponde a um conjunto de comportamentos observáveis, que se identificam pelo tratamento 
diferencial e desigual de pessoas ou de grupos em razão das suas origens, pertenças, aparências (...) ou opiniões, reis ou supostas" (Taguieff, 1997, p. 131).

Expressões pejorativas são ouvidas, como: “aquele marginalzinho ali cheio de tatuagem aí, ó. Aquela tatuagem de porta de cadeia" (estagiária de serviço social apud Luna, 2009, p. 320). Mesmo não estando ligado ao tráfico de drogas ou a qualquer tipo de ação ilegal, uma tatuagem já suscita especulações sobre a pessoa, merecendo desconfianças e, assim, diferenciação no tratamento. "O estigma que tais pessoas carregam proporciona-lhe o pior que pode haver em termos de tratamento 'não humanizado' porque é nesses casos que o medo, a repugnância e a ojeriza que causam nos outros sequer são disfarçados" (Luna, 2009, p. 321).

Auxiliares de enfermagem que podem maltratar pacientes, por meio, aparentemente, de práticas 'inocentes', também são capazes de discutir com alguns médicos em prol dos usuários. Porém, é comum acontecer de acompanhantes de pacientes maltratarem auxiliares de enfermagem. Acontece, por exemplo, quando um acompanhante pede satisfação e informação sobre o estado de saúde de um paciente ao auxiliar de enfermagem diversas vezes, mesmo quando o auxiliar repete que apenas o médico pode apresentar o parecer da situação. Muitas vezes o acompanhante humilha, fala mal, grita, reclama da demora do diagnóstico, culpando até o auxiliar de enfermagem, mas quando o médico aparece e o auxiliar lembra ao acompanhante que é ele, o médico, que deve oferecer as informações, o acompanhante só falta beijar a mão do médico, ou seja: ele se exalta, é agressivo, exige providências diante do auxiliar de enfermagem; mas diante do médico apresenta uma postura humilde, submissa e solícita ao que ele fala. E sempre aparecem situações em que a presença do médico é fundamental, porém muitas vezes ele não está presente. No turno da noite, por exemplo, o médico, que descansa no dormitório, só pode ser procurado em caso de extrema urgência, e assim, quem carrega o serviço todo nas costas é o pessoal de enfermagem, que tem de aguentar tudo (Luna, 2009).

É nesse hospital público, diz Luna (2009), parafraseando a fala de uma auxiliar de enfermagem, que tem gente espalhada em todo lugar: é gente nas macas, no corredor, tudo apertado, pessoas acidentadas e doentes; se brincar, tem gente até para pendurar igual a cabide. Gente tratada como não gente. Os subcidadãos...

\section{As ações dos assistentes sociais no campo da saúde: proteger a vida, deixando viver...}

Luna (2009) deixa claro que a estagiária de serviço social acredita que incentivar a humanização do atendimento dos profissionais da saúde por meio da educação continuada é uma saída possível para a melhora e o aumento da qualidade da saúde pública. Desse modo, da portaria à direção, da recepcionista ao 
médico, todos deveriam participar de projetos de educação que estimulassem a criação de vínculos do profissional com os usuários, como também que trabalhassem a autoestima e a motivação do próprio trabalhador.

Embora interessante, a proposta da estagiária "não leva em consideração que a desvalorização dos pacientes da ralé é algo objetivo, que independe da boa vontade de alguns agentes envolvidos" (Luna, 2009, p. 326). Seria necessário, então, problematizar a existência da 'ralé' como classe social e moral precária, para poder tocar no cerne do problema do atendimento não humanizado de forma mais eficaz. Considera-se que os próprios interessados, a 'ralé', por suas condições objetivas "que lhes aprisionam numa eterna busca por remediar as necessidades primárias de sobrevivência, são 'amputados' politicamente" (Luna, 2009, p. 326), ou seja, além de não serem vistos como classe social, não conseguem articular politicamente suas reivindicações por melhoria no atendimento.

Como precondição para conseguir exigir direitos e mudanças, é preciso ao sujeito da 'ralé' já ser reconhecido e tratado como indivíduo portador de direitos e valorizado. Como pessoa não habituada a ser tratada como cidadã, por isso mesmo muitas vezes não sabe como exigir benefícios - apesar de lhe serem garantidos em lei -, pois precisaria, para isso, de planejamento de ações, disciplina etc., características que ela não possui. "Em outros termos, a arma contra a má-fé da saúde que a ralé em primeira instância deveria usar exigiria que ela não fosse ela mesma" (Luna, 2009, p. 327). É aqui que um projeto eficaz de humanização deve, primordialmente, abordar esse drama. "Apenas reconhecendo a sua existência em nossa sociedade é que será possível almejar projetos bem-sucedidos, que (...) envolvam instituições e toda a sociedade na possibilidade de mudanças a médio e longo prazo" (Luna, 2009, p. 327). É nesse contexto que colocamos a importância da atuação do assistente social como um dos modos de reverter essa situação degradante.

Inicialmente, é importante contextualizar a atual política de saúde no Brasil, considerando que desde a década de 1990 o Estado brasileiro, sob influência da hegemonia neoliberal, deve deixar de ser o responsável direto pelo desenvolvimento econômico e social, transferindo para o setor privado as atividades que antes eram de sua responsabilidade. Assim, a política de saúde construída na década de 1980 passa a ser desconstruída, com a saúde vinculada ao mercado, destacando as parcerias com a sociedade civil, que se tornaria responsável por assumir os custos da crise. Nessa conjuntura, Bravo (2009) sinaliza que questões comprometem a possibilidade de avanço do SUS como política social, destacando: “o desrespeito ao princípio de equidade na alocação de recursos públicos pela não unificação dos orçamentos federal, estaduais e municipais" (Bravo, 2009, p. 100-101); a não integralidade entre prevenção e atenção curativa, "havendo prioridade para a assistência médico-hospitalar em detrimento das ações de promoção e proteção da saúde" 
(Bravo, 2009, p. 101); a remuneração por produção, denunciada como fator incontrolável de corrupção; a divisão do SUS em dois: o hospitalar e o básico.

O projeto saúde, novamente articulado ao modelo médico assistencial privatista, pautado na política de ajuste, objetiva conter os gastos com racionalização da oferta. Cabe ao Estado garantir um mínimo, por meio do pacote básico, aos que não podem pagar (caráter focalizado e não universalizante do direito à saúde) - de modo a ficar para o setor privado o atendimento aos que podem pagar (estímulo à contratação de planos de saúde) - e descentralizar com isenção a responsabilidade do poder central (Bravo, 2009).

Como efeito, o modelo assistencial prevalecente no país caracteriza-se pela prática 'hospitalocêntrica', pelo individualismo e abandono da prevenção e promoção da saúde, pela baixa resolubilidade etc., resultando em um modelo ineficiente, custoso e desumano, não correspondendo às necessidades da população usuária e aviltando a prática profissional.

Os dois projetos políticos em disputa na área da saúde passam a apresentar diferentes requisições para o serviço social: o projeto privatista vem requisitando ao assistente social, entre outras demandas, a seleção socioeconômica dos usuários; atuação psicossocial por meio de aconselhamento; assistencialismo por meio da ideologia do favor; predomínio de práticas individuais etc. Em contrapartida,

(...) o projeto da reforma sanitária apresenta como demandas que o assistente social trabalhe as seguintes questões: democratização do acesso às unidades e aos serviços de saúde; estratégias de aproximação das unidades de saúde com a realidade; trabalho interdisciplinar; ênfase nas abordagens grupais; acesso democrático às informações e estímulo à participação popular (Bravo, 2009, p. 26).

Nesse caso, o exercício profissional do assistente social não deve desconsiderar as dimensões subjetivas vividas pelo usuário. Também não se deve reduzir à defesa de uma suposta particularidade do trabalho desenvolvido pelos assistentes sociais nas diferentes especialidades da medicina. As novas diretrizes das diversas profissões têm ressaltado a importância de se formarem trabalhadores de saúde para o SUS com visão generalista e não fragmentada. Para isso, foram discutidas e articuladas atribuições e competências para os assistentes sociais.

As atribuições e competências dos profissionais de serviço social, sejam aquelas realizadas na saúde, sejam em outro espaço sócio-ocupacional, são orientadas e norteadas por direitos e deveres constantes no Código de Ética Profissional e na Lei de Regulamentação da Profissão, que devem ser observados e respeitados, tanto pelos profissionais quanto pelas instituições empregadoras.

Começamos com os Parâmetros para atuação de assistentes sociais na política da saúde (Conselho Federal de Serviço Social, 2010), que têm como objetivo referenciar a intervenção dos profissionais de serviço social na área da 
saúde, lembrando que essa atuação, na contemporaneidade, pode seguir duas propostas contraditórias, apontadas anteriormente. Nos parâmetros, quatro eixos de atuação são considerados: atendimento direto aos usuários; mobilização, participação e controle social; investigação, planejamento e gestão; assessoria, qualificação e formação profissional.

Em relação ao atendimento direto aos usuários, as ações educativas constituem a oportunidade para trabalhar, junto da 'ralé', aqueles aspectos que mantêm tal classe exatamente numa situação de 'ralé'. Com as ações educativas, que "consistem em orientações reflexivas e socialização de informações realizadas por meio de abordagens individuais, grupais ou coletivas ao usuário, família e população de determinada área programática" (Conselho Federal de Serviço Social, 2010), é possível retomar a ideia de que a saúde (humanizada e de qualidade) é um direito, e que deve ser reivindicada, considerando-se que tal direito é sufocado e esse interesse descuidado, principalmente pelo fato de ser direcionado, geralmente, a uma classe desprivilegiada, desconsiderada e desvalorizada socialmente. A 'ralé' tem direito de ser bem atendida pelo Estado e pelos profissionais que fazem parte da saúde pública: deve ser tratada como gente.

Nessa perspectiva, o profissional de serviço social deve utilizar, segundo Vasconcelos (1997), a prática reflexiva, com o propósito de facilitar aos usuários a análise das situações experienciadas por meio da reflexão crítica estimulada pelo assistente social. Assim, a partir da captação do movimento da realidade social, é possível que o usuário participe, conscientemente, do processo de transformação dessa realidade como ser histórico.

Finalmente, o próprio assistente social deveria refletir sobre a hierarquia valorativa entre os tipos humanos e, também, entre as diversas profissões, como forma de legitimar a importância social de sua profissão, principalmente diante de outras profissões e profissionais de áreas consideradas socialmente mais importantes. A desconstrução dessa hierarquia deve começar a partir dele mesmo, legitimada em suas práticas profissionais cotidianas.

\section{Considerações finais}

O campo da saúde, fruto das lutas populares e sindicais, foi um dos espaços que mais conquistaram êxito com relação ao fortalecimento dos direitos sociais, o que se refletiu no texto constitucional de 1988, o qual apresentou um novo arranjo para a área da saúde, oferecendo uma configuração particular em aspectos ético-políticos fundamentais - que culminou na universalização do direito à saúde, a partir da legitimação da garantia do acesso pleno e igualitário aos serviços de saúde, sem quaisquer critérios de exclusão e de discriminação. Nesse contexto, a proposta do SUS veio fundamentada na concepção ampliada de saúde, entendendo que a doença e a saúde não são situações fixas e imutáveis, mas, ao contrário, dinâmicas, impossíveis de 
serem interpretadas pela interação mecânica de partes do organismo humano - constatando-se a insuficiência do modelo biologicista/biomédico para responder aos processos de saúde e doença inerentes à vida moderna. Compreende-se, então, que fatores socioeconômicos, culturais e ambientais são determinantes das situações de vida e saúde (Nogueira e Mioto, 2009). ${ }^{5}$

A preocupação com a universalidade e a justiça social, o crescimento dos direitos de cidadania e o papel do Estado no provimento da atenção social são assuntos comuns que merecem atenção - assim como o discurso do reconhecimento da saúde como um direito social e o entendimento de sua garantia como dever do Estado excedem uma abordagem insuficiente e centrada em um discurso meramente acrítico e normativo (Nogueira e Mioto, 2009).

Percebemos, então, que o modelo assistencial prevalecente no Brasil caracteriza-se pela prática 'hospitalocêntrica', pelo individualismo e abandono da prevenção e promoção da saúde, e que o modelo privatista da saúde está em disputa com o projeto de Reforma Sanitária. Diante dessa realidade, nosso interesse de discussão focaliza a atuação dos assistentes sociais no campo da saúde junto à 'ralé', no sentido de que poderiam garantir o direito a essa classe de indivíduos à vida, 'fazendo-a viver' e não 'deixando-a morrer' - assim como o direito a serviços de saúde de qualidade e humanizados. Ora, a proteção da vida humana, o 'fazer viver', deveria ser um dos mais eficazes objetivos do Estado, que se ocuparia, por exemplo, da gestão da saúde via políticas públicas de qualidade, na medida em que estas se tornassem preocupações políticas. Mas se toda essa prática atende o 'fazer viver', inclusive sendo responsável direto pelo aumento da expectativa de vida das pessoas, como se exerce o 'deixar morrer'? Esse 'fazer viver' inclui todos os grupos sociais? E se inclui, a inclusão é igualitária? Percebemos, em nossas análises, que o incremento da vida da população não se separa da produção contínua da exclusão, do desdém, da morte. Nas instituições de saúde pública, pode ocorrer que o 'fazer viver', paradoxalmente, transforme-se em 'deixar morrer'.

Para Agamben (1998, apud Duarte, 2008), vivemos sob a contínua necessidade de redefinir o limiar entre o que está dentro da ordem política (a vida que deve ser protegida) e o que está fora (a vida descartável e matável), ou seja: vivemos cada vez mais sob o jugo da dinâmica da proteção e destruição da vida por meio de sua inclusão excludente do aparato jurídico. Para verificar a validade de tal hipótese, Duarte (2008) afirma que basta conferir as estatísticas a respeito do número gigantesco de seres humanos que, mesmo quando incluídos no âmbito jurídico-político da cidadania, encontram-se, de fato, dela excluídos, involuntariamente, por motivos diversos: o caso da 'ralé' estrutural; os refugos humanos, segundo Bauman (2005). É a vida desprotegida, que pode ser descartada e até assassinada, sem que se cometa delito.

No contexto brasileiro, a 'ralé', diante de um Estado que inclui excluindo e que, apesar de apresentar discursos de igualdade, legitima a desigualdade 
social -, tendo acesso a uma educação que desmistifique sua condição de 'ralé', poderá construir para si mesma uma consciência sanitária, ou seja, uma percepção de que a saúde é um direito da pessoa e um direito da comunidade, independentemente de sua origem social. Para a 'ralé', tal educação, com clara intenção de libertação em prol de uma nova cultura que enfatize a sua participação no conhecimento crítico da sua realidade, potencializando-a como sujeito para a construção de estratégias coletivas, a colocará como partícipe da construção de sua própria cidadania.

Os assistentes sociais, por meio do trabalho e das relações sociais, que objetivam romper com práticas discriminatórias, excludentes e alienantes, com os modos capitalistas de pensar e agir, precisam executar ações que resultem num processo educativo e não apenas possibilitem acesso a bens e serviços. É exatamente pelo conjunto da prática exercida pelos assistentes sociais que a profissão de serviço social é respeitada ou não, reconhecida ou não, valorizada ou não (Vasconcelos, 2009).

Vasconcelos (2009) destaca que as necessidades acolhidas pelos assistentes sociais, em sua maioria recebidas via encaminhamentos, referem-se à realização dos serviços prestados pelas instituições de saúde e à dinâmica das próprias instituições ou, ainda, à doença em si. “Por outro lado, as demandas manifestadas por acesso aos serviços e por recursos são consideradas demandas individuais/particulares de usuários que, por diferentes motivos, não conseguem inserção na rotina institucional" (Vasconcelos, 2009, p. 251). Tais necessidades, por se apresentarem individualmente, não são tidas como demandas coletivas. "As demandas que extrapolam o controle burocrático, os serviços institucionais, ou seja, demandas por educação em saúde, prevenção, participação e controle social, dos serviços prestados, ficam negligenciadas" (Vasconcelos, 2009, p. 251). São essas demandas desconsideradas que os assistentes sociais devem priorizar em sua prática profissional.

O assistente social, junto à 'ralé', deverá priorizar ações de reflexão, superando a simples divulgação de conhecimentos. Deverá priorizar a lógica da reflexão que possibilita desmistificar, fortalecer, democratizar e politizar. Desse modo, o indivíduo da 'ralé' vai além de sua condição de passivo, de objeto, assumindo sua condição de sujeito, de cidadão. No campo da saúde, a reflexão proporcionará a retomada da ideia de que a saúde humanizada e de qualidade é um direito que deve ser reivindicado. 
Resumen Este artículo problematiza la singularidad de la desigualdad social brasileña, productora de una 'plebe' estructural y legitimada por una jerarquía valorativa que separa personas en gente y subgente, ciudadanos y subciudadanos; personas que deben ser vistas y respetadas, por un lado, y personas despreciadas, desvalorizadas, por otro. Posteriormente, abordamos cómo tiene lugar la reproducción del esquema de la desigualdad social en la salud pública, considerada de pésima calidad y que contradice, en la práctica, las premisas constitucionales sobre las cuales se creó el Sistema Único de Salud, no beneficiando la propuesta idealizada en su esencia de garantizar ciudadanía inclusiva e igualitaria. Finalmente, proponemos reflexiones en torno a la actuación de los asistentes sociales en la salud pública a partir de la atención directa de los usuarios, principalmente por medio de acciones educativas, considerándolas como una oportunidad para trabajar, junto a la 'plebe', aspectos que mantienen tal clase exactamente en una situación de subciudadanía y, por eso, receptora de atención deshumana en los servicios públicos de salud.

Palabras clave desigualdad social; salud pública; actuación de los asistentes sociales.

\section{Notas}

${ }^{1}$ Universidade Estadual da Paraíba, Programa de Pós-Graduação em Serviço Social, Campina Grande, Paraíba, Brasil.

$<$ ninjosibn@gmail.com>

Correspondência: Universidade Estadual da Paraíba, Programa de Pós-Graduação em Serviço Social, Rua Baraúnas, Universitário, CEP 58429-500, Campina Grande, Paraíba, Brasil.

2 "Dentre as sociedades desenvolvidas, inclusive, é a mais rica dentre elas, os EUA, a que apresenta maior índice de desigualdade e exclusão" (Souza, 2003a, p. 58).

${ }^{3}$ Souza (2009) informa que o termo usado 'ralé' não é para humilhar ou ofender as pessoas, mas para chamar a atenção, de modo provocativo, ao abandono social e político vivenciado por toda uma classe de indivíduos.

${ }^{4} \mathrm{O}$ habitus - modos plásticos e flexíveis de perceber, fazer, pensar, sentir e ser - pressupõe um conjunto de noções que antecede a ação, esta última constituindo-se nas práticas dos agentes no interior do campo social, ou seja: o habitus produz práticas, individuais e coletivas; a prática é ação, é a exteriorização do habitus, em conformidade com os esquemas engendrados pela história, "sinal incorporado de uma trajetória social (...) e de um campo social" (Bourdieu, 1983, p. 45).

5 "Dentre os diversos fatores determinantes das condições de saúde incluem-se os condicionantes biológicos (idade, sexo, características herdadas pela herança genética), o meio físico (que inclui condições geográficas, características da ocupação humana, disponibilidade e qualidade de alimento, condições de habitação), assim como os meios socioeconômico e cultural, que expressam os níveis de ocupação, renda, acesso à educação formal e ao lazer, os graus de liberdade, hábitos e formas de relacionamentos interpessoais, a possibilidade de acesso aos serviços voltados para a promoção e recuperação da saúde e a qualidade de atenção pelo sistema prestado" (Nogueira e Mioto, 2009, p. 219). 


\section{Referencias}

BAUMAN, Zygmunt. Vidas desperdiçadas. Rio de Janeiro: Jorge Zahar Editor, 2005.

BOURDIEU, Pierre. Sociologia. São Paulo: Ática, 1983.

BOURDIEU, Pierre. A distinção: crítica social do julgamento. São Paulo: Edusp; Porto Alegre: Zouk, 2007.

BRAVO, Maria I. S. Política de saúde no Brasil. In: MOTA, Ana E. et al. (orgs.). Serviço social e saúde: formação e trabalho profissional. 4. ed. São Paulo: Cortez; Brasília: Opas, OMS, Ministério da Saúde, 2009. p. 88-110.

CONSELHO FEDERAL DE SERVIÇO SOCIAL (CFESS). Parâmetros para atuação de assistentes sociais na politica de saúde. Brasília: CFESS, 2010.

COSTA, Jurandir F. Desiguais na vida e na morte. Folha de S.Paulo, São Paulo, 22 maio 1994. Caderno Mais!, p. 6-15.

DUARTE, André M. De Michel Foucault a Giorgio Agamben: a trajetória do conceito de biopolítica. 2008. Disponível em: <http:// works.bepress.com/cgi/viewcontent.cgi?article $=1016 \&$ context $=$ andre_duarte $>$. Acesso em: 12 dez. 2013.

LUNA, Lara. 'Fazer viver e deixar morrer': a má-fé institucional da saúde pública no Brasil. In: SOUZA, Jessé (org.). A ralé brasileira: quem é e como vive. Belo Horizonte: Editora UFMG, 2009. p. 305-327.

MACHADO, Eduardo P.; NORONHA, Ceci V. A polícia dos pobres: violência policial em classes populares urbanas. Sociologias, Porto Alegre, ano 4, n. 7, p. 188-221, jan.-jun. 2002.

NOGUEIRA, Vera M. R.; MIOTO, Regina C. T. Desafios atuais do Sistema Único de Saúde-SUS e as exigências para os assistentes sociais. In: MOTA, Ana E. et al. (orgs.). Serviço social e saúde: formação e trabalho profissional. 4. ed. São Paulo: Cortez; Brasília: Opas, OMS, Ministério da Saúde, 2009. p. 218-241.

SOUZA, Jessé. (Não)Reconhecimento e subcidadania, ou o que é ser gente? Lua Nova, São Paulo, n. 59, p. 51-73, $2003 a$.

SOUZA, Jessé. A construção social da subcidadania: para uma sociologia política da modernidade periférica. Belo Horizonte: Editora UFMG; Rio de Janeiro: Iuperj, 2003b.

SOUZA, Jessé (org.) A invisibilidade da desigualdade brasileira. Belo Horizonte: Editora UFMG, 2006.

SOUZA, Jessé (org.). A ralé brasileira: quem é e como vive. Belo Horizonte: Editora UFMG, 2009.

SOUZA, Jessé. Os batalhadores brasileiros: a nova classe média ou nova classe trabalhadora. Belo Horizonte: Editora UFMG, 2010.

TAGUIEFF, Pierre-André. O racismo. Lisboa: Instituto Piaget, 1997.

VASCONCELOS, Ana M. Serviço social e prática reflexiva. Revista Em Pauta, Rio de Janeiro, n. 10, p. 131-181, jul. 1997.

VASCONCELOS, Ana M. Serviço social e práticas democráticas na saúde. In: MOTA, Ana E. et al. (orgs.). Serviço social e saúde: formação e trabalho profissional. 4. ed. São Paulo: Cortez; Brasília: Opas, OMS, Ministério da Saúde, 2009. p. 242-272.

Recebido em 24/07/2015

Aprovado em 20/12/2016 